\title{
Acquired pendular nystagmus with oscillopsia in multiple sclerosis: a sign of cerebellar nuclei disease
}

\author{
JÜRGEN C. ASCHOFF, ${ }^{1}$ B. CONRAD, AND H. H. KORNHUBER \\ From the Department of Neurology, University of Ulm, W. Germany
}

SYNOPSIS In an unselected series of 644 cases of multiple sclerosis, 25 cases with acquired pendular nystagmus were found. Ten additional cases of pendular nystagmus in multiple sclerosis were investigated, and four cases from the literature are analysed. Acquired pendular nystagmus is purely sinusoidal in form, ceases with eye closure, is accompanied by oscillopsia, often monocular and vertical in direction, and never accompanied by optokinetic inversion. This is different from congenital nystagmus. Acquired pendular nystagmus in multiple sclerosis shows a high correlation with holding tremor of head and arm and with trunk ataxia, and must therefore be viewed as a result of lesions of cerebellar nuclei or their fibre connections with the brain-stem. Supporting evidence is discussed. The results fit into a theory of cerebellar function according to which the cerebellar nuclei are involved in the maintenance of positions.

Pendular nystagmus has been defined as oscillatory eye movements in which fast and slow phases cannot be differentiated. The most common and best known clinical manifestation is congenital pendular nystagmus. Pendular nystagmus and congenital nystagmus are not equivalent, however, because congenital nystagmus is frequently not pendular, and pendular nystagmus may be acquired. Examples of the latter are spasmus nutans (Raudnitz, 1897), miners' nystagmus (Ohm, 1954), pendular nystagmus in multiple sclerosis (Uhthoff 1890; Ohm, 1949; Nathanson et al., 1955; Kornhuber, 1966), and pendular nystagmus in conjunction with palatal myoclonus (Alajouanine et al., 1935; Guillain, 1938; Bender et al., 1952; Nathanson, 1956; Chokroverty and Barron, 1969). Relatively few cases of acquired pendular nystagmus associated with multiple sclerosis have been adequately investigated. For the definition of various kinds of nystagmus including spontaneous, fixation and gaze nystagmus the reader is referred to Jung and Kornhuber (1964).

In an unselected series of 644 patients with multiple sclerosis acquired pendular nystagmus was found in 25 patients. The symptoms of this

Address for reprints: University Hospital, Department of Neurology, Steinhövelstraße 9, $79 \mathrm{Ulm} /$ Donau, West Germany. acquired pendular nystagmus in multiple scleros 雴음 will be described in an attempt to determine the localization of the pathological process under lying the phenomenon. Preliminary results have been published (Kornhuber, 1969; Aschoff et ale 1970). Since the completion of this series if 1969, 10 additional cases of acquired pendular nystagmus have been investigated, the results of which fully confirm the conclusion drawn from this series of 25 patients.

\section{METHODS}

In the course of three years, 644 unselected patients suffering from multiple sclerosis were investigated, of whom 25 exhibited pendular nystagmus. Thirteen of these were male and 12 were female, with an average age of 39.4 years. In 19 patients the illness had an acute onset and showed frequent exacerbations. In the remaining six patients the disease followed a more chronic course. Diagnosis of multiple sclerosis was confirmed by typical spinal fluid findings, clinical symptoms, and disease progress. They all lived with their families and required only temporary treatment in the hospital.

Eye movements were recorded by means of $\mathrm{AC}$ or $\mathbb{N}$ DC electrooculography (electronystagmography) or is photo-electronystagmography. The former method N was used to record horizontal and vertical eye movements (Beckman electrodes) with the eyes both 570 
TABLE

SUMMARY OF FINDINGS IN 25 PATIENTS WITH MULTIPLE SCLEROSIS SHOWING PENDULAR NYSTAGMUS*

\begin{tabular}{|c|c|c|c|c|c|c|c|c|c|c|c|c|c|}
\hline \multirow[t]{2}{*}{$\mathrm{Nr}$. } & \multirow[t]{2}{*}{$\begin{array}{l}\text { ğx } \\
\text { ŏ }\end{array}$} & \multicolumn{3}{|c|}{$\begin{array}{l}\text { Direction of PN } \\
\text { with foreward gaze }\end{array}$} & \multirow{2}{*}{ 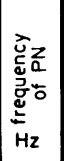 } & \multirow{2}{*}{$\begin{array}{c}\text { amplitude } \\
\text { of PN } \\
\text { (degrees) }\end{array}$} & \multirow{2}{*}{ 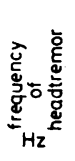 } & \multirow{2}{*}{ 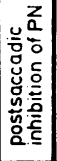 } & \multicolumn{2}{|c|}{$\begin{array}{l}\text { enhancement of } \\
\text { PN-amplitude by }\end{array}$} & \multirow{2}{*}{ 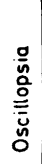 } & \multirow{2}{*}{ 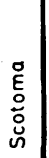 } & \multirow{2}{*}{$\begin{array}{l}\bar{\sigma} \frac{2}{3} \\
\frac{n}{2} \\
\% \\
\%\end{array}$} \\
\hline & & right eye & & left eye & & & & & & & & & \\
\hline 1 & $\begin{array}{l}44 \\
8\end{array}$ & & & $v$ & 3.2 & & 3,0 & & & & & + & $\begin{array}{l}\text { le } 10-20 \\
\text { ri } 100\end{array}$ \\
\hline 2 & $\begin{array}{c}37 \\
q\end{array}$ & 0 & $<$ & $\infty$ & 2,7 & & $\varnothing$ & & & & + & $\varnothing$ & $10-20$ \\
\hline 3 & $\begin{array}{r}35 \\
8 \\
8\end{array}$ & & $<$ & & 4,0 & $>2^{\circ}$ & $(+)$ & + & $\varnothing$ & & + & $\varnothing$ & $10-20$ \\
\hline 4 & $\begin{array}{c}37 \\
q\end{array}$ & $\infty$ & $>$ & & 4,1 & $>2^{\circ}$ & $\varnothing$ & + & $\varnothing$ & $\varnothing$ & + & $\varnothing$ & $10-20$ \\
\hline 5 & 29 & & $=$ & & 3,0 & $6-7^{\circ}$ & $(+)$ & + & $\varnothing$ & + & & $\varnothing$ & $\begin{array}{lrr}\text { le } & 10 \\
\text { ri } & 0\end{array}$ \\
\hline 6 & $\begin{array}{l}42 \\
q\end{array}$ & & $=$ & & 3.6 & $>2^{\circ}$ & 3.7 & & & & $\infty$ & $\varnothing$ & $80-100$ \\
\hline 7 & $\begin{array}{c}44 \\
0\end{array}$ & ) & $\gg$ & $\rightarrow$ & 2,9 & $>2^{\circ}$ & $\varnothing$ & & & & + & $\infty$ & $\begin{array}{ll}\text { le } & 80 \\
\text { ri } & 10\end{array}$ \\
\hline 8 & $\begin{array}{c}34 \\
9\end{array}$ & 0 & $\ggg$ & 0 & 2,9 & $3-4^{\circ}$ & $(+)$ & + & $\varnothing$. & $\varnothing$ & $\varnothing$ & $\varnothing$ & $\begin{array}{ll}\text { le } & 80 \\
\mathrm{ri} & 20\end{array}$ \\
\hline 9 & $\begin{array}{c}45 \\
8\end{array}$ & 0 & $<$ & 0 & 3,8 & $>2^{\circ}$ & 3.5 & + & + & + & + & $\varnothing$ & $10-20$ \\
\hline 10 & $\begin{array}{l}55 \\
6\end{array}$ & 0 & $=$ & 0 & 2.9 & & 2,7 & + & $\varnothing$ & + & $\varnothing$ & $\varnothing$ & $10-20$ \\
\hline 11 & $\underset{f}{26}$ & $\longrightarrow$ & $<$ & $\longleftarrow$ & 4.6 & $>2^{\circ}$ & 2,6 & + & $\varnothing$ & $\varnothing$ & & + & $10-20$ \\
\hline 12 & $\begin{array}{c}58 \\
8\end{array}$ & $\leftrightarrow$ & & nucleation & 5.4 & $>2^{\circ}$ & $\varnothing$ & + & $\varnothing$ & $\varnothing$ & + & $\varnothing$ & $>10$ \\
\hline 13 & $\begin{array}{c}39 \\
6\end{array}$ & $\Gamma$ & $=$ & & 3.0 & & 3,0 & & & & + & $\varnothing$ & $10-20$ \\
\hline 14 & 46 & 0 & & - & 3.0 & & 2.8 & & & & & $\varnothing$ & $10-20$ \\
\hline 15 & 35 & & $=$ & 1 & 29 & $>2^{\circ}$ & 3.0 & & + & & $\varnothing$ & $\varnothing$ & 80 \\
\hline 16 & 31 & $\longrightarrow$ & $>$ & $\infty$ & 28 & $2-3^{\circ}$ & $(+)$ & + & $\varnothing$ & & + & $\varnothing$ & $10-20$ \\
\hline 17 & 4 & $\infty$ & $=$ & $\leftrightarrow$ & 2,0 & 20 & & + & 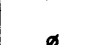 & & 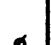 & శ. & $0-30$ \\
\hline 17 & 6 & $\infty$ & $=$ & $\infty$ & . 3,8 & $>2$ & 3,2 & + & $\infty$ & 8 & 8 & 81 & $10-20$ \\
\hline 18 & $\begin{array}{l}46 \\
f\end{array}$ & $\longleftrightarrow$ & & • & 4.1 & $>2^{\circ}$ & 4,2 & & $\varnothing$ & $\varnothing$ & + & $\varnothing$ & $10-20$ \\
\hline 19 & $\begin{array}{l}35 \\
q\end{array}$ & & $=$ & 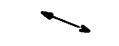 & 4,6 & & $\varnothing$ & + & & & + & $\varnothing$ & $10-20$ \\
\hline 20 & $\begin{array}{c}25 \\
\sigma^{\circ}\end{array}$ & $\longleftrightarrow$ & & $\longleftrightarrow$ & 4,5 & $>2^{\circ}$ & 4.0 & + & + & + & $\varnothing$ & + & $10-20$ \\
\hline 21 & $\begin{array}{l}31 \\
8\end{array}$ & $\infty$ & $<$ & $\infty$ & 5.0 & $>2^{\circ}$ & 4.1 & + & + & & + & $\varnothing$ & $10-20$ \\
\hline 22 & $\begin{array}{l}42 \\
8\end{array}$ & $\infty$ & $\ll$ & $\infty$ & 3,2 & $3-4^{\circ}$ & 3.2 & + & + & + & + & $\Phi$ & $\begin{array}{l}l e>10 \\
\mathrm{ri} \quad 20\end{array}$ \\
\hline 23 & $\begin{array}{c}31 \\
8\end{array}$ & $\leftrightarrow$ & $=$ & $\leftrightarrow$ & 4,5 & & $\varnothing$ & + & & & + & $\varnothing$ & $10-20$ \\
\hline 24 & $\begin{array}{c}27 \\
q\end{array}$ & & & & & & $(+1)$ & & & & + & $\varnothing$ & $10-20$ \\
\hline 25 & $\begin{array}{l}45 \\
q\end{array}$ & $\theta$ & $=$ & $\theta$ & & & $\varnothing$ & & & & & & $60-80$ \\
\hline & & I & & & $\angle 0$ & & & + & & & + & $\varnothing$ & le 100 \\
\hline & & & & & & & & & & & & & \\
\hline & & & & & 5.0 & & & & & & + & $\infty$ & $10-20$ \\
\hline & & 0 & & & 5,6 & & & & $\varnothing$ & & + & 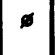 & $\begin{array}{l}\text { le g } \\
\text { ri } 20\end{array}$ \\
\hline & & & $\ggg$ & & 3.3 & $>1^{\circ}$ & & & $\varnothing$ & & + & $\varnothing$ & $\begin{array}{l}\text { le } 8 \\
\text { ri } 20\end{array}$ \\
\hline
\end{tabular}

* Four cases from the literature are summarized at the bottom of the Table. 
opened and closed. Recordings were made of saccadic and smooth pursuit movements as well as of optokinetic, rotational and postrotational nystagmus. Recordings were also made over a longer period of time of visual fixation, and relaxation with the eyes closed. For analysis of pendular nystagmus, the direction, inter-eye-phase-relationship, constancy of frequency and amplitudes, influence of fixation, gaze direction, alertness, and rotational acceleration were evaluated. All 25 patients were investigated at least twice in the course of several months (up to two years).

\section{RESULTS}

ANALYSIS OF PENDULAR NYSTAGMUS A summary of the nystagmographic findings, of oscillopsia, scotomata, and visual acuity is given in the Table. Four cases of pendular nystagmus in multiple sclerosis, which have been fully described in the literature, are included at the bottom of this Table.

Pendular nystagmus during visual fixation reveals a wide range of parameters. It may be monocular or binocular, and may show a large variety of directions from linear (horizontal or vertical) through eliptical or circular movements and even different directions for each eye. On nystagmographic recordings acquired pendular nystagmus in multiple sclerosis always shows a purely sinusoidal form (Fig. 1). The direction of the pendular movements was similar in both eyes in 21 patients but different in four patients (cases 4, 5, 7, 9, see Table). Binocular acquired pendular nystagmus was vertical in six patients as opposed to horizontal in 15 cases. Both eyes are phase-locked in their oscillating pendular movements (except for one patient). In this latter case (no. 10) the pendular nystagmus during leftward gaze consisted of in-phase movements, whereas during gaze to the right these movements were $90^{\circ}$ out of phase.

The average frequency of pendular nystagmus was $3.9 \mathrm{~Hz} \pm 0.05$ and was the same for both eyes in a binocular pendular nystagmus. Within the limits of experimental error, the frequencies remained constant throughout testing, and were unaffected by direction of gaze, fixation, and alertness.

The amplitude of pendular nystagmus was usually less than $2^{\circ}$ but was as great as 6 to $7^{\circ}$ in one patient. In three patients the amplitude was so small that it could be detected and analysed only by means of ophthalmoscopic examination In contrast with the constancy of frequency there was a marked variability of amplitudes depending on the direction of gaze (Fig. 1a), and of fixation (Fig. 1b, c). Optokinetic and vestibularo stimuli may also affect the amplitude (Table) With the eyes closed, pendular nystagmus invariably ceases. It might, however, reappear? after a latency of some 10 seconds at the same frequency but with a much reduced amplitude

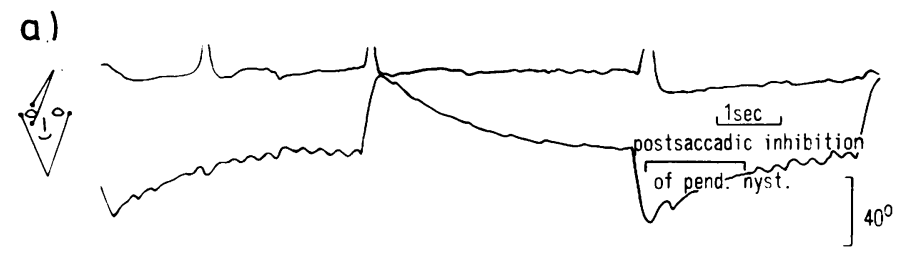

FIG. 1. Electronystagmographic recordings of pendular nystagmus. (a) Binocular horizontal pendular nystagmus with large amplitudes on gaze to the left. No pendular nystagmus on gaze to the right. Postsaccadic

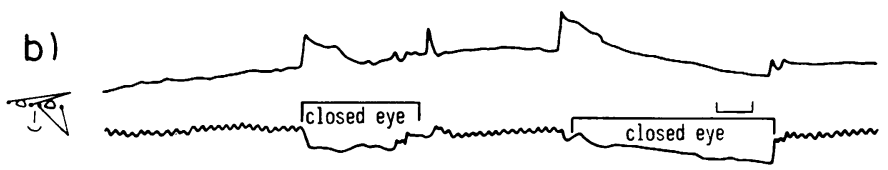
inhibition after saccadic eye movements. (b) Left eye monocular pendular horizontal nystagmus during fixation which disappears when the eyes are closed. (c) Right eye monocular vertical

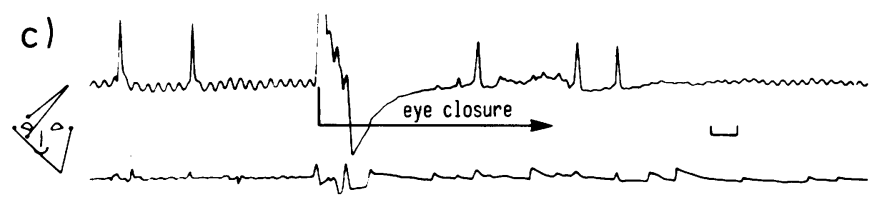
pendular nystagmus during fixation. Pendular nystagmus ceases after eye closure but reappears with small amplitude after 10-15 seconds. 
(Fig. 1c). In addition, a postsaccadic inhibition of pendular nystagmus was observed in most patients. After a saccadic eye movement, pendular nystagmus is inhibited for one to two seconds. This can be shown not only in electronystagmographic recordings, but is also observed by patients as a transient inhibition of their oscillopsia after rapid eye movements (Fig. 1a).

Seventy per cent of the patients with pendular nystagmus complained of oscillopsia, especially when fatigued or fixating distant objects. Visual acuity was reduced to $20 \%$ in nearly all cases, also in three patients (cases $6,15,25$ ) the reduction of visual acuity was minimal. In three patients (cases $1,7,8$ ), with asymmetrical or predominantly monocular pendular nystagmus, there was a greater loss of visual acuity in the oscillating eye. Reduction in visual acuity was at least in part due to the pendular nystagmus because there were cases without any sign of optic nerve lesion.

Pendular nystagmus can be altered during an acute exacerbation or by a remission of the underlying disease. In one patient, a previously observed pendular nystagmus ceased after the remission of an acute exacerbation; in another case pendular nystagmus was observed to develop after an acute exacerbation.

Gaze nystagmus was present in 23 of the 25 patients, gross dysmetria of horizontal saccadic eye movements in 17 patients. In none of them has inversion of optokinetic nystagmus been observed, as is often seen in congenital pendular nystagmus.

NEUROLOGICAL SYMPTOMS A total of 644 patients with multiple sclerosis were examined, 25 of whom showed pendular nystagmus. A comparison between the latter and the 619 patients without pendular nystagmus revealed no correlation with duration of illness (average 12.7 years for patients with and 11.7 years for patients without pendular nystagmus), or with age (average 43.5 years for patients with and $44 \cdot 1$ years for patients without pendular nystagmus). There was also no significant difference between the two groups as far as frequency and severity of spinal symptoms (spasticity, paresis, autonomic dysfunction) are concerned.

On the other hand, there was a significant difference for cerebellar symptoms between the two groups. Patients with pendular nystagmus

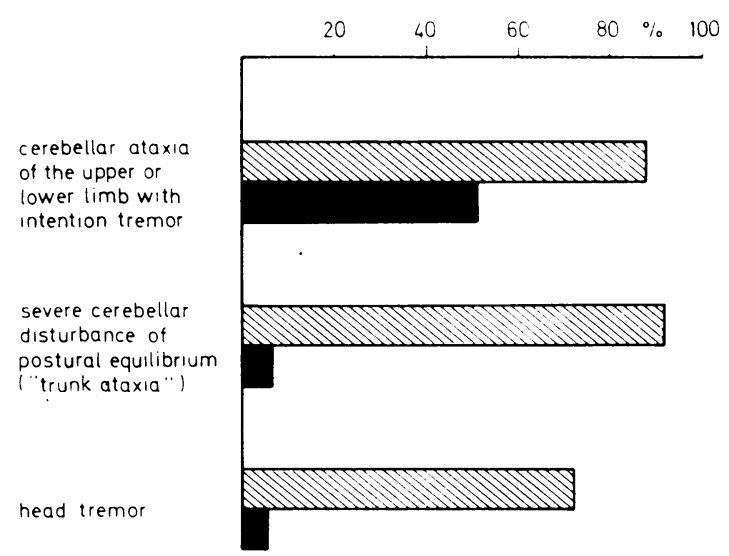

NUMBER OF PATIENTS WITH MULTIPLE SCLEROSIS

FIG. 2. Comparison of cerebellar symptoms in patients with $(\mathbb{Z})$ and without $(\square)$ pendular nystagmus. Pendular nystagmus shows a high correlation with symptoms due to cerebellar lesions.

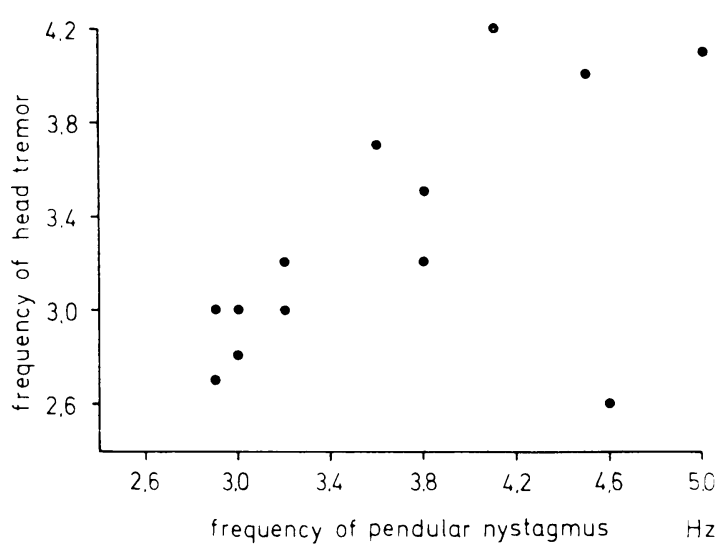

FIG. 3. Frequencies of head tremor versus frequencies of pendular nystagmus in 13 patients suffering from multiple sclerosis, and showing head tremor and pendular nystagmus.

always suffered from severe cerebellar symptoms such as trunk ataxia, head tremor, intention tremor, or the cerebellar type of speech disturbance. Figure 2 shows the frequency of the main cerebellar symptoms for patients with and without pendular nystagmus, as well as optic disc findings and scotomas. The difference in cerebellar symptoms between the two groups is 
highly significant-for instance, trunk ataxia $6 \%$ versus $92 \%$, and head tremor $5 \%$ versus $72 \%$.

The frequency of head tremor shows some correlation with the frequency of the pendular nystagmus (see Table and Fig. 3). Most often the frequency of pendular nystagmus is slightly higher than the frequency of the head tremor (eight of 13 cases, in the other five patients the frequencies were virtually identical within $0 \cdot 1 \mathrm{~Hz}$ ). There was, however, no significant relationship between the direction of the pendular nystagmus and that of the head tremor. Therefore, pendular nystagmus cannot be explained as the vestibular compensation of the eyes for head tremor. The head tremor is evoked by active head holding and disappears in the relaxed supine position.

Case 2 with elliptical pendular nystagmus died of pulmonary embolism. Necropsy showed typical patchy demyelinizations throughout the spinal cord and in all samples of forebrain, cerebellum and brain-stem.

After completion of the statistical analysis for the 644 patients, 10 additional cases of acquired pendular nystagmus in multiple sclerosis were seen. They completely confirmed our previous findings in the series of the first 25 cases. Acquired pendular nystagmus can also be present as an isolated symptom. Among the 10 latter cases not included in the Table there was a patient who complained only of oscillopsia. A monocular horizontal pendular nystagmus was found, and from the patient's history the diagnosis of multiple sclerosis in full remission (except for the pendular nystagmus) was established. Acquired pendular nystagmus with oscillopsia can thus remain as an isolated symptom in multiple sclerosis in the remission phase.

\section{DISCUSSION}

Acquired pendular nystagmus has been found in approximately $4 \%$ of our patients with multiple sclerosis, which represents a higher proportion than previously presumed in the literature, although Uhthoff in 1890 observed pendular nystagmus in conjunction with multiple sclerosis in seven out of 100 investigated patients. A detailed description of pendular nystagmus in multiple sclerosis is available in only three cases by Nathanson et al. (1955), one case by $\mathrm{Ohm}$
(1949), and one case by Kornhuber (1966). Bender (1965) in his work on oscillopsia additionally has described acquired pendular nystagmus with vertical, horizontal, and rotatory directions as the course of oscillopsia whereby lesions of the brain-stem have been predominantly described as the underlying disease. Other forms of abnormal eye movements such as ocular dysmetria, ocular myoclonus, or spasmus nutans should not be confused with pendular nystagmus.

Diagnostic differentiation between acquired pendular nystagmus in multiple sclerosis and congenital pendular nystagmus can be made as follows: congenital pendular nystagmus is seldom purely sinusoidal; it lacks a vertical component with the rare exception of the autosomal dominant inherited pendular nystagmus (Dichgans and Kornhuber, 1964) and the amplitude and direction of the nystagmus are bilaterally similar. Acquired pendular nystagmus in multiple sclerosis, in contrast, frequently exhibits vertical components, and usually there are dissimilarities of direction and amplitude. Inversion of optokinetic nystagmus-typical forn many cases of congenital nystagmus-never appears in acquired pendular nystagmus. Finally, oscillopsia and neurological symptoms except head tremor are not found in patients witho congenital nystagmus. Acquired pendular nystagmus in multiple sclerosis resembles more closely the acquired form of pendular nystagmus of miners than congenital nystagmus, with the exception of the rare autosomal-dominantly inherited form which shows several similarities to the acquired pendular nystagmus in multiple sclerosis such as vertical components, head tremor, and lack of optokinetic inversion (Dichgans and Kornhuber, 1964).

The highly significant correlation between cerebellar symptoms and pendular nystagmus found in our patients indicates that pendular nystagmus is a cerebellar symptom. Of the two main structures within the cerebellum (cortex and nuclei) the cerebellar cortex will not elicit pendular nystagmus either by stimulation (Cohen et al., 1965) or by lesions (Kornhuber, 1968; Aschoff and Cohen, 1972). Therefore, the cerebellar nuclei or their fibre connections with the brain-stem are obviously the structures the lesions of which may cause pendular nystagmus.

For this conclusion there is supporting evidence 
from four sources: (1) from the analogy with postural tremor, (2) from our necropsy case, (3) from electrical stimulation experiments of the cerebellar nuclei in man, and (4) from the few cases of pendular nystagmus in patients with palatal myoclonus due to vascular lesions cited in the literature.

ANALOGY OF PENDULAR NYSTAGMUS AND POSTURAL TREMOR Acquired pendular nystagmus in multiple sclerosis is present only during fixation and ceases with eye closure. Thus pendular nystagmus can be interpreted as a holding tremor of the eyes similar to the holding tremor of the head or of the limbs produced by lesions of the cerebellar nuclei or of their fibre connections with the brain-stem and thalamus. Kornhuber $(1971,1973)$ has viewed the maintenance of position as a function of the cerebellar nuclei. He pointed out that the cerebellar nuclei are analogous in function as well as in anatomical connections with the vestibular nuclei, the function of which is certainly to hold a position. The difference between the cerebellar and vestibular nuclei is that the vestibular nuclei hold the position of the whole body with respect to gravity while the cerebellar nuclei hold the position of parts of the body with respect to cerebral commands.

NECROPSY FINDINGS IN CASE 2 Widespread demyelination in many parts of the nervous system is common in multiple sclerosis, and necropsies, therefore, are not particularly helpful in localizing those nervous structures whose destruction leads to pendular nystagmus. However, it is remarkable that, in the necropsy of our series, there were extensive lesions in the cerebellum. Lesions in the cerebellum do not belong to the common localizations of plaques in multiple sclerosis. Lumsden (1970) reported that only $6 \%$ of the plaques are localized in the cerebellum.

OSCILLATING EYE MOVEMENTS DURING ELECTRICAL STIMULATION OF CEREBELLAR NUCLEI IN MAN The only report of a pendular nystagmus being elicited by electrical stimulation comes from Nashold et al. (1969). They observed oscillating eye movements in man after electrical stimulation of the medial cerebellar nuclei. The fact that other authors investigating the destruction of cerebellar nuclei (Ferrier and Turner, 1894; Sachs and Finscher, 1927; Botterell and Fulton, 1938b; Carrea and Mettler, 1947; Krayenbühl and Siegfried, 1969; Guglielmino and Strata, 1971) or the destruction of cerebellar peduncles (Ferrier and Turner, 1894; Ferraro and Barrera, 1936; Walker and Botterell, 1937; Botterell and Fulton, 1938a) did not especially mention pendular nystagmus is no contradiction to the positive findings, because these authors did not pay particular attention to changes in eye movements nor to different kinds of nystagmus.

PENDULAR NYSTAGMUS AND PALATAL MYOCLONUS AFTER VASCULAR LESIONS Pendular nystagmus closely resembling pendular nystagmus in multiple sclerosis has been described in patients with palatal myoclonus (Bender et al., 1952; Nathanson, 1956; Chokroverty and Barron, 1969). Necropsies performed on these patients showed in all cases lesions in the dentate nucleus or the brachium conjunctivum, and in addition in the inferior olive (Alajouanine et al., 1935; Guillain, 1938; Bender et al., 1952; Nathanson, 1956). The inferior olive appears to have no effect on the oculomotor system (Wilson and Magoun, 1945). Therefore only the lesions within the dentate nucleus or the brachium conjunctivum can account for the pendular nystagmus.

Anatomically, there are known to be connections between the dentate nucleus and the oculomotor nuclei (Carpenter and Strominger, 1964), and between the fastigial nucleus and the pontine gaze centre for horizontal eye movements (Walberg et al., 1962). Another projection is known from the dentate and interpositus nuclei onto the supranuclear gaze centre for vertical and rotatory eye movements (Mehler et al., 1958). For a summary of these projections between cerebellar nuclei and supranuclear gaze centres relevant for eye movements see Aschoff (1973).

Lesions within the cerebellar nuclei or their efferent projections to the supranuclear centres for horizontal or vertical eye movements, therefore, interact with the holding function of these centres. Depending on which of the cerebellar nuclei is affected by the lesion, a vertical, horizontal, or elliptical pendular nystagmus is 
produced. The direct connection from deep cerebellar to oculomotor nuclei may be responsible for some asymmetry of pendular nystagmus between the two eyes. Oscillopsia, finally, is the immediate consequence of oscillatory eye movements.

\section{REFERENCES}

Alajouanine, T., Thurel, R., and Hornet, T. (1935). Un cas anatomo-clinique de myoclonies vélo-pharyngées et oculaires. Revue Neurologique, 64, 853-872.

Aschoff, J. C. (1973). Reconsideration of the oculomotor pathway. In The Neurosciences. Edited by F. O. Schmitt. Third Study Volume. Rockefeller University Press: New York.

Aschoff, J. C., Conrad B., and Kornhuber, H. H. (1970). Acquired pendular nystagmus in multiple sclerosis. Proceedings of the Bárány Society, Amsterdam, 1970, pp. 127-132.

Aschoff, J. C., and Cohen, B. (1972). Cerebellar ablations and spontaneous eye movements in monkey. Bibliotheca Ophthalmologica, 82, 169-177.

Bender, M. B. (1965). Oscillopsia. Archives of Neurology, 13, 204-213.

Bender, M. B., Nathanson, M., and Gordon, G. G. (1952). Myoclonus of muscles of the eye, face, and throat. Archives of Neurology and Psychiatry, 67, 44-58.

Botterell, E. H., and Fulton, J. F. (1938a). Functional localization in the cerebellum of primates. 1. Unilateral section of the peduncles. Journal of Comparative Neurology, 69, 31-46.

Botterell, E. H., and Fulton, J. F. (1938b). Functional localization in the cerebellum of primates. 2. Lesions of midline structures (vermis) and deep nuclei. Journal of Comparative Neurology, 69, 47-62.

Carpenter, M. B., and Strominger, N. L. (1964). Cerebellooculomotor fibers in the rhesus monkey. Journal of Comparative Neurology, 123, 211-229.

Carrea, R. M. E., and Mettler, F. A. (1947). Physiologic consequences following extensive removals of the cerebellar cortex and deep cerebellar nuclei and effect of secondary cerebral ablations in the primate. Journal of Comparative Neurology, 87, 169-288.

Chokroverty, S., and Barron, K. D. (1969). Palatal myoclonus and rhythmic ocular movements: a polygraphic study. Neurology (Minneap.), 19, 975-982.

Cohen, B., Goto, K., Shanzer, S., and Weiss, A. H. (1965). Eye movements induced by electric stimulation of the cerebellum in the alert cat. Experimental Neurology, 13, 145-162.

Dichgans, J., and Kornhuber, H. H. (1964): Eine seltene Art des hereditären Nystagmus mit autosomal-dominantem Erbgang und besonderem Erscheinungsbild: vertikale Nystagmuskomponente und Störung des vertikalen und horizontalen optokinetischen Nystagmus. Acta Genetica et Statistica Medica, 14, 240-250.

Ferraro, A., and Barrera, S. E. (1936). Effects of lesions of the juxtarestiform body (I.A.K. bundle) in Macacus Rhesus monkeys. Archives of Neurology and Psychiatry, 35, 13-29.

Ferrier, D., and Turner, W. A. (1894). A record of experiments illustrative of the symptomatology and degenerations following lesions of the cerebellum and its peduncles and related structures in monkeys. Philosophical Transactions of the Royal Society of London B, 185, 719-778.

Guglielmino, S., and Strata, P. (1971). Cerebellum and atonia of the desynchronized phase of sleep. Archives Italiennes de Biologie, 109, 210-217.

Guillain, G. (1938). The syndrome of synchronous and rhythmic palato-pharyngo-laryngo-oculo-diaphragmatic myoclonus. Proceedings of the Royal Society of Medicine, 31, 1031-1038.

Jung, R., and Kornhuber, H. H. (1964). Results of electronystagmography in man: the value of optokinetic, vestibular, and spontaneous nystagmus for neurologic diagnosis and research. In The Oculomotor System, pp. 428-488. Edited by M. B. Bender. Harper and Row: New York.

Kornhuber, H. H. (1966). Physiologie und Klinik des zentralvestibulären Systems. In Hals-Nasen-Ohren-Heilkunde. Ein kurzgefasstes Handbuch in drei Bänden, Vol. 3, Part 3, pp. 2150-2351. Edited by J. Berendes, R. Link, and F. Zollner. Thieme: Stuttgart.

Kornhuber, H. H. (1968). Neurologie des Kleinhirns. (Abstract.) Zentralblatt für die gesamte Neurologie und Psychiatrie, 191, 13.

Kornhuber, H. H. (1969). Physiologie und Klinik des vestibulären Systems. (Abstracts.) Archiv für Klinische und Experimentelle Ohren-Nasen- und Kehlkopfheilkunde, 194, 150-151. (Full article: pp. 111-148.)

Kornhuber, H. H. (1971). Motor functions of cerebellum and basal ganglia: the cerebellocortical saccadic (ballistic) clock, the cerebellonuclear hold regulator, and the basato ganglia ramp (voluntary speed smooth movement) generator. Kybernetik, 8, 157-162.

Kornhuber, H. H. (1973). Cerebral cortex, cerebellum, ando basal ganglia: an introduction to their motor functions. In The Neurosciences. Edited by F. O. Schmitt. Third Study Program. Rockefeller University Press: New York.

Krayenbühl, H., and Siegfried, J. (1969). La chirurgie stéréotaxique du noyau dentelé dans le traitement des hyperkinesies et des états spastiques. Neuro-Chirurgie, 15, 51-58.

Lumsden, C. E. (1970). The neuropathology of multiple sclerosis. In Handbook of Clinical Neurology, Vol. 9, pp. 217-309. Edited by P. J. Vinken and G. W. Bruyn. North-Holland: Amsterdam.

Mehler, W. R., Vernier, V. G., and Nauta, W. J. H. (1958). Efferent projections from dentate and interpositus nuclei in primates. (Abstracts.) Anatomical Record, 130, 430-431.

Nashold, B. S., Jr., Slaughter, D. G., and Gills, J. P. (1969). Ocular reactions in man from deep cerebellar stimulation and lesions. Archives of Ophthalmology, 81, 538-543.

Nathanson, M. (1956). Palatal myoclonus. Archives of Neurology and Psychiatry, 75, 285-296.

Nathanson, M., Bergman, P. S., and Bender, M. B. (1955). Monocular nystagmus. American Journal of Ophthalmolog., 40, 685-692.

Ohm, J. (1949). Pendelförmiger Nystagmus bei multipler Sklerose. Nervenarzt, 20, 224-227.

Ohm, J. (1954). Nachlese aus dem Gebiete des Augenzitterns: der Bergleute. Enke: Stuttgart.

Raudnitz, R. W. (1897). Zur Lehre vom Spasmus nutans. Jahrbuch für Kinderheilkunde, 45, 145-176, 416-459.

Sachs, E., and Fincher, E. F., Jr. (1927). Anatomical and physiological observations on lesions in the cerebellar nuclei in Macacus Rhesus. Brain, 50, 350-356. 
Uhthoff, W. (1890). Untersuchungen über Augenstörungen bei Multipler Sklerose. Archiv für Psychiatrie und Nervenkrankheiten, 21, 390-399.

Walberg, F., Pompeiano, O., Westrum, L. E., and HauglieHanssen, E. (1962). Fastigioreticular fibers in the cat. Journal of Comparative Neurology, 119, 187-199.
Walker, A. E., and Botterell, E. H. (1937). The syndrome of the superior cerebellar peduncle in the monkey. Brain, 60 , 329-353.

Wilson, W. C., and Magoun, H. W. (1945). The functional significance of the inferior olive in the cat. Journal of Comparative Neurology, 83, 69-77. 